\title{
Parent use of complementary medicine remedies and services for the management of respiratory tract infection in children: a qualitative study
}

This article was published in the following Dove Press journal: Journal of Multidisciplinary Healthcare

\section{S Lucas $\mathbb{1 D}^{1}$ \\ S Kumar (D) \\ MJ Leach $\left(\mathbb{D}^{2}\right.$ \\ A Phillips $\mathbb{D}^{1}$}

'School of Health Sciences, Department of Health Sciences, University of South Australia, Adelaide, South Australia, Australia; ${ }^{2}$ Department of Rural Health, University of South Australia, Adelaide, South Australia, Australia
Correspondence: S Lucas School of Health Sciences, University of South Australia, North Tce, Adelaide 5001 , South Australia, Australia

Tel +6I 488901240

Fax +6I 0883022853

Email sandra.lucas@mymail.unisa.edu.au
Background: The use of complementary and alternative medicine (CAM) is increasing globally, in both adults and children. A common condition where CAM is used in children is acute respiratory tract infection (ARTI). However, limited information exists regarding specific CAM modalities used in children, and the factors that influence a parent's decision to use CAM for ARTI in children. This research aimed to address this knowledge gap.

Method: This research used a qualitative descriptive approach. Parents residing in Greater Melbourne, Australia, who had children aged from 0-12 years, and had used CAM for treating ARTI in their children in the last 12 months, were eligible to participate. Parents' perspectives were captured using individual semi-structured interviews, which were then transcribed verbatim. Data were analysed using content analysis.

Results: Twenty-four families were interviewed. Several strategies to improve trustworthiness were implemented. Three themes underpinning the parents' decision to use CAM emerged from the data: safety, internal drivers and external drivers. Parents used a breadth of different treatments, predominantly food as medicine, followed by aromatherapy and other CAM remedies typically found in the kitchen, to manage ARTI in their children. Parents often used both CAM practitioners and mainstream medicine to manage ARTI in their children. While mainstream medicine was typically used to rule out any sinister pathology, CAM was often used as a frontline treatment option, with food as medicine (e.g. soups) dominating. This was due in part to concerns regarding the negative aspects of pharmaceutical use. Parents utilised a diverse range of information sources to inform their decisionmaking, including friends, families and the internet; traditional sources of research evidence were generally not used.

Conclusion: Child safety was a major factor influencing a primary carer's decision to utilise CAM for ARTI. The safety and effectiveness of remedies utilised by parents now warrants further investigation.

Keywords: barriers, traditional complementary integrated medicine, decision-making, paediatric, qualitative descriptive, respiratory infection

\section{Introduction}

Complementary and alternative medicine (CAM) is utilised by children across the globe for both the prevention and management of myriad conditions and illnesses. ${ }^{1-2}$ CAM refers to a group of systems and practices considered outside the domain of conventional medicine, which are used to prevent or treat illness and/or to promote health and wellbeing. ${ }^{3}$ Italia, Wolfenstetter, Teuner ${ }^{4}$ report that, depending on nationality and CAM modality, there is a wide variation in CAM usage among children, ranging from 
$10.9-87 \%$ (for lifetime use) and 8-48.5\% (for current use). In Australia, the reported prevalence of CAM use ranges from $18-68.9 \%$. $^{2,5-8}$ Internationally, while CAM use is most prevalent among middle-aged adults, ${ }^{9}$ between $30-51 \%$ of the general paediatric population reportedly use CAM for a range of health conditions. ${ }^{1-2,5,10,11}$

As surrogate decision makers, parents often have to consider a range of factors when deciding to use CAM for their child. One such factor is the interaction with significant others, including partners, friends, health professionals and teachers. In health care more generally, consumer health care decisions are often influenced by interactions with family, friends, neighbours, ${ }^{12}$ parents, ${ }^{13}$ the internet, ${ }^{14}$ and health care providers. ${ }^{15}$ This is proposed to be similar for the use of CAM. ${ }^{16,17}$ From an ecological point of view, the media too can play an essential role in parental decision-making. ${ }^{14,18}$ Through a crosssectional study of 129 parents in Florida, USA, Knapp, Madden, Marcu, Wang, Curtis, Sloyer, Shenkman ${ }^{14}$ demonstrated that the internet was a primary information source for $21 \%$ of parents seeking knowledge on their child's health, with $60 \%$ of parents using the internet as a secondary source of information. This is particularly troubling as decisions about CAM use that are based on information gained from everyday/lay media have been reported to be either inaccurate or incomplete. ${ }^{19,20}$

Health orientation is another factor influencing CAM utilisation, with evidence from cross-sectional and qualitative studies indicating users of CAM generally desire a greater sense of control over their health. ${ }^{21,22}$ Data from the Australian Census of Population and Housing $(n=21.5$ million) and the Australian National Health Survey $(n=20,788)$ indicate that CAM users adopt healthier diets and lifestyles relative to non-CAM users, with users reporting greater fruit consumption and levels of physical activity, and lower rates of smoking than non-users. ${ }^{10}$ While studies to date have provided much-needed insight into the typical adult CAM consumer, there is little known about the paediatric CAM consumer.

According to the National Center for Complementary and Integrative Health, National Center for Health Statistics $^{1}$ of all US children that have used CAM in the past 12 months, CAM was most frequently used in children to treat back and neck pain $(6.7 \%)$, head and chest colds $(6.6 \%)$, other musculoskeletal complaints $(4.8 \%)$, and anxiety and stress (4.2\%). Similarly, for Australian children, the most common reason for utilising CAM was to prevent illness $(39 \%)$ and to treat musculoskeletal
$(22 \%)$, respiratory $(20 \%)$ and skin conditions $(18 \%))^{6}$ While specific data regarding CAM usage in Australian children is unavailable, the findings of a 2018 systematic review indicate that the most common CAM modalities used for ARTI by parents (internationally) is food and plant-based medicines ${ }^{23}$

Although acute respiratory tract infection (ARTI) was not the most common reason for parents using CAM for their children, it is the most common reason for parents visiting a general health practitioner, ${ }^{24,25}$ with $6-7$ million visits reported annually (between March 2002 and March 2004) in Australia. ${ }^{24,26,27}$ Furthermore, acute lower respiratory tract infection is the leading cause of child mortality, globally. ${ }^{28}$

For the purpose of this research, acute respiratory tract infection (ARTI) was defined as any of the following symptoms: cough, sore throat, fever, blocked nose, and infant feeding problems due to mucus. The conditions included upper and lower respiratory tract infections, such as a coughs and colds (also known as common cold, coryza, acute nasopharyngitis, acute pharyngorhinitis), ${ }^{29}$ as well as laryngitis, pharyngitis/tonsillitis, acute rhinitis, acute rhinosinusitis, acute otitis media, pneumonia, bronchitis and bronchiolitis. $^{24,30}$

Given the economic, psychosocial and physical implications of ARTI, and the central role of the parent in making decisions regarding the use of CAM for the management of this condition in children, it is important to identify the CAM treatments that are used by parents for the management of ARTI in children, as well as the factors that influence a parent's decision to select these modalities. This research served to address both aims.

\section{Methods}

The theoretical framework that informed this research was the pragmatic framework, ${ }^{31-33}$ with pragmatism described as a worldwide view that arises out of action, situation, and consequences. ${ }^{32}$ This framework was chosen as it

recognise[s] that there are many different ways of interpreting the world and undertaking research, [and] that no single point of view can ever give the entire picture and that there may be multiple realities ${ }^{34}$

This research framework serves to further our understanding of parental decision-making regarding the use of CAM for the treatment of ARTI in children. 


\section{Research questions}

The research questions this study aimed to answer were:

1. What CAM interventions are utilised by parents for the treatment of ARTI in children from birth up to the age of 12 years?

2. What factors influence a parent's decision to use CAM for the treatment of ARTI in their children from birth up to the age of 12 years?

\section{Study design}

A qualitative descriptive (QD) design was chosen as the primary objective of the study was to obtain an accurate portrayal of people's characteristics or circumstances and/ or the frequency with which certain phenomena occur. ${ }^{35}$ Further, QD research produces findings that are close to the data ${ }^{36}$ by striving to keep the story as close as possible to the participant's intentions, and to generate a product that presents facts in everyday language. ${ }^{36,37}$ The COREQ (COnsolidated criteria for REporting Qualitative research) Checklist was used to guide the reporting of this study. ${ }^{38}$

\section{Participants}

Participants were recruited using maximum variation purposive sampling. ${ }^{36}$ As with any qualitative research, there was no pre-determined sample size. The final sample size (24 families) was established when the research team acknowledged that ongoing data collection was unlikely to garner new information ${ }^{36,37}$ and the phenomena under exploration were adequately assessed. Participants were primary carers (i.e. mother, father, grandparent or significant other [foster parent, aunt, uncle]) of one or more children aged between 0 and 12 years. Participants had to reside within Greater Melbourne, Australia, and must have utilised CAM (either self-prescribed or recommended by a health professional [i.e. biomedical and/or CAM practitioner]) for the management of ARTI in their children in the past 12 months. Excluded were carers/parents of children with chronic immune conditions, such as cystic fibrosis or leukaemia, and carers/parents that did not comprehend the English language or were unable to provide informed consent.

\section{Method of approach}

A Facebook page was generated exclusively for this research. The page provided general information about the study, including details on how to contact the researcher for further information. A link to the Facebook page was shared on parenting and natural medicine Facebook groups/or pages, and was included on recruitment flyers. Principles and preschool leaders of government schools and preschools in the Greater Melbourne area, which utilised the mobile application "Tiqbiz/Flexbuzz" for parent communication, were contacted by email. The email introduced the research and sought assistance to promote the study to parents by circulating a recruitment flyer via the mobile application or an electronic newsletter. All recruitment material invited potential participants to contact the researcher either by email or private message (via the Facebook page).

\section{Data collection}

Data were collected through face-to-face semi-structured interviews, conducted by the first author (SL). Development of the interview agenda was informed by the research questions, a systematic literature review, ${ }^{23}$ and other pertinent literature on CAM and ARTI. Prior to the commencement of the interviews, piloting of the interview agenda/process was undertaken using a convenience sample of four parents residing in the Greater Melbourne area. The aim of the pilot was to test for clarity, the order of questions, conciseness and relevance. Feedback from the pilot resulted in only minor changes to the wording of some items. On completion of the pilot, data were discarded to ensure they were not used in the final analysis.

Demographic data were collected by the interviewer prior to the commencement of the semi-structured interview, using a customized questionnaire. The interviews were guided by a pre-determined 29-item interview agenda (Table 1). The interviews were performed at a time and place convenient for participants (e.g. home or workplace of a participant). Interviews ranged from $21-75$ mins; the average interview time was 34 mins. Data collected during the interviews included demographic information, types of CAM used to treat acute respiratory tract infections (e.g. herbal medicine, vitamins, chiropractic) and factors influencing decision making regarding the use of CAM. Field notes were taken during and immediately after the interviews to assist in confirming the accuracy of the interview transcripts and to aid data interpretation. The field notes were primarily used for cross-checking purposes, and were not used in the data analysis or the reporting of results. All interviews were audiotaped and transcribed verbatim. The first author checked all transcriptions for accuracy. Repeat interviews and cross-checking of transcripts were not 
Table I Semi-structured interview agenda for parents

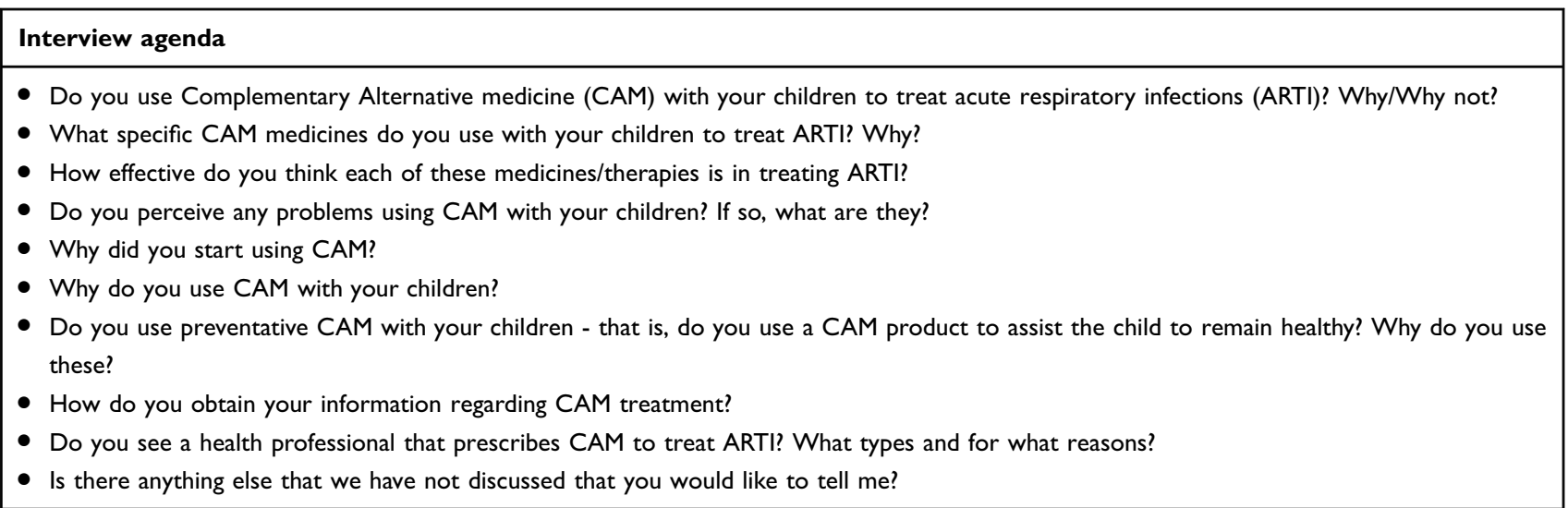

possible, due to time restraints and ongoing availability of participants.

\section{Data analysis}

Interview data were managed utilising NVivo ${ }^{\mathrm{TM}}$ software (version 10) and analysed using inductive content analysis. The content analysis comprised three-stages: (1) preparing (i.e. immersing in the data and obtaining a sense of whole; selecting the unit of analysis; deciding on the analysis of manifest content or latent content), (2) organising (i.e. using open coding to create categories, group codes under higher order headings, and formulate a general description of the research topic through the generation of categories and subcategories), and (3) reporting (i.e. presenting the results utilizing models, such as mind maps). ${ }^{39-41}$ Rigour was maintained by ensuring the study/data were credible (i.e. using multiple coders [SL, SK, ML]), transferable (i.e. providing a thick, rich description of the methods, data collection and analysis), dependable (i.e. triangulating the data-field notes obtained through observation), and confirmable (i.e. identifying the study limitations).

\section{Role of the researcher}

Qualitative research, by its very nature, can foster close relationships between researchers and participants. While this can be a strength, it is also important that the researcher does not influence the participant's perspectives. The first author is a qualified Nurse with extensive experience in the field of CAM. She believed that parents routinely used CAM for children with ARTI and parents of children were sufficiently knowledgeable about their preferences and decision-making process when choosing CAM. Such assumptions were made based on personal experiences (gained through interaction with parents in the community), discussion with peers as well as from research (i.e. a systematic review ${ }^{23}$ ). Such influences cannot be eliminated, nor can they be entirely controlled. As a means of managing this, a number of strategies were implemented. These include participating in training initiatives to upskill the researcher in the conduct and reporting of qualitative research; through reflection on the findings from the research process, and through regular discussions with research supervisors.

\section{Ethics and privacy}

Ethics approval was granted by the Human Research Ethics Committees of the University of South Australia (ID: 0000035018) and the Department of Education and Training (Victoria) (ID: 2016_003142). Research participants provided informed written consent after reading the participant information sheet and prior to data collection. A unique identification number and pseudonym were allocated to each participant to protect participant privacy. Participants had the right to refuse participation or withdraw from the study at any time without repercussion.

\section{Results}

\section{Demographic data}

Twenty-six parents (from 24 families) participated in the interviews. The primary care parents interviewed were female $(100 \%)$, noting that the two fathers (no data obtained) attended the interview as part of a couple and not as individuals. The mean age of parents was 46 years, with a age range of 26-54 years. Most parents were born in Australia (76\%) and resided in a suburban environment $(67 \%)$. English was the most commonly reported language 
spoken at home $(92 \%)$. The number of years that the parent had utilised CAM ranged from 2 years to 51 years, with a mean of 23 years. Most parents held a Bachelor's degree qualification or higher (75\%), were in paid employment $(90 \%)$ and did not have private insurance $(45 \%)$ (see Table 2).

A total of 46 children were included in the 24 families, of which $50 \%$ were female. The ages of the children ranged from 11 months to 19 years, and all families had at least one child aged 12 years or under. The amount of time the children had used CAM ranged from 6 months $(n=3,6 \%)$, to the child's entire life $(n=23,50 \%)$.

\section{CAM remedies/treatments used}

Parents reported a broad and diverse range of CAM therapies, including acupuncture, anthroposophic medicine, aromatherapy, ayurvedic, chiropractic, diet and nutritional therapy, energy medicine, herbal medicine, homoeopathy, kinesiology, massage, naturopathy, osteopathy, traditional Chinese medicine, and vitamin and mineral supplementation (Table 3). The most frequently utilised CAM remedies were food as medicine $(n=31,67 \%)$, aromatherapy $(n=30$, $65 \%)$, vitamin $C(n=27,58 \%)$, honey $(n=25,54 \%)$ and garlic $(n=23,50 \%)$ (Table 3$)$. The least frequently utilised CAM remedies were Ivy leaf $(n=1,2 \%)$, traditional teas $(n=1,2 \%)$ and Chinese cupping $(n=1,2 \%)$. Most parents used CAM in combination with other CAM therapies $(87 \%$, $\mathrm{n}=21$ ), for example chiropractic treatment and herbal medicines. A CAM treatment was used singularly in $8 \%(\mathrm{n}=2)$ of cases, and most used CAM with biomedicine (80\%, $\mathrm{n}=19$ ). Biomedicine encompassed the terms allopathic medicine, orthodox medicine, conventional medicine, mainstream medicine, general medical practitioners (GP) and medical specialist. For the purpose of consistency, in this manuscript, the term biomedicine is used henceforth.

\section{Consultations by health practitioners for ARTI by parents}

There were 12 different CAM practitioners consulted by families (Figure 1). Different CAM practitioners for ARTI were utilised by parents, depending on the symptom picture, with an average of 2.5 distinct CAM practitioners consulted per family (range 1-6). Naturopaths were the most frequently consulted CAM practitioners $(n=14$, $58 \%)$, followed by chiropractors $(n=8,33 \%)$ and osteopaths $(n=7,29 \%)$ (Figure 1). Not all families consulted CAM practitioners for the management of ARTI in their children. Seven families (29\%) chose to use self-prescribed CAM remedies. Of the $21(85 \%)$ parents that consulted GP's for ARTI, one (4\%) reported that they would exclusively consult a GP for ARTI, while 20 (84\%) would consult a GP, if necessary, after a CAM practitioner.

\section{Qualitative data - factors influencing parent decision-making}

Different factors with certain commonalities seemingly influence a parent's decision to utilize CAM for ATRI. The factors identified as drivers of parents' CAM use for the management of acute respiratory tract infections in their children were grouped into three broad categories. These categories were (1) Safety, (2) Internal drivers and (3) External drivers (Figure 2). Each broad category was organised with a series of subcategories, and elements were identified within these subcategories. The subcategories for Safety were: safety of CAM and safety of biomedicine. For Internal drivers, the subcategories included: personal health philosophy, the effectiveness of CAM, and past experience with biomedicine and CAM. For External drivers, the subcategories were: information sources and physical barriers. Each category impacted the parent's decision making concerning their use of CAM for ARTI in their children (Figure 2).

\section{Safety}

Safety was a broad concept, which encompassed several important and critical factors that parents reflected on from the perspective of balancing the benefits of using CAM and the risks and side-effects of using CAM and/or biomedical treatments. The role of safety in the decisionmaking process highlights the value of and the importance underpinning this important concept from the perspective of the parents. Further consideration of the safety of their child related to the determination of when consultation with a biomedical practitioner may be necessary. Therefore, two components of safety, CAM and biomedicine, were identified.

\section{Safety of CAM}

Included in the subcategory "safety of CAM" were two key elements. These elements were the risks of side effects and the quality of CAM remedies. Generally, this subcategory refers to the safety of CAM products. Most parents $(n=21,87 \%)$ did not perceive any problems with utilising CAM remedies for the treatment of ARTI in their children, reporting that, they perceived CAM remedies to be safe: 
Table 2 Demographic characteristics of primary carer $(n=26)$

\begin{tabular}{|c|c|c|}
\hline Variable & Category & Value \\
\hline Gender, n (\%) & $\begin{array}{l}\text { Female } \\
\text { Male } \\
\text { Total }\end{array}$ & $\begin{array}{l}24(100) \\
2(8) \\
26\end{array}$ \\
\hline Age, mean \pm SD [years] & Range: $26-54$ & $4 I \pm 6.89$ \\
\hline Residential location, n (\%) & $\begin{array}{l}\text { Inner city (0-10 km from CBD) } \\
\text { Suburbs (more than } 10 \mathrm{~km} \text { from CBD) } \\
\text { Rural suburban (acreage properties) }\end{array}$ & $\begin{array}{l}3(13) \\
16(67) \\
5(20)\end{array}$ \\
\hline Number of parents in household, $n(\%)$ & $\begin{array}{l}\text { One } \\
\text { Two }\end{array}$ & $\begin{array}{l}9(37) \\
15(63)\end{array}$ \\
\hline Education, n (\%) & $\begin{array}{l}\text { Year } 12 \\
\text { Certificate } \\
\text { Diploma } \\
\text { Bachelor's degree } \\
\text { Postgraduate certificate/diploma/ } \\
\text { Honours } \\
\text { Master's Degree }\end{array}$ & $\begin{array}{l}1(4) \\
3(13) \\
2(8) \\
9(37) \\
3(13) \\
6(25)\end{array}$ \\
\hline Employment status, $n(\%)^{*}$ & $\begin{array}{l}\text { Full-time } \\
\text { Part-time } \\
\text { Casual } \\
\text { Student } \\
\text { Volunteer }\end{array}$ & $\begin{array}{l}5(20) \\
9(37) \\
8(33) \\
7(29) \\
1(4)\end{array}$ \\
\hline Gross annual household income, $\mathrm{n}(\%)$ & $\begin{array}{l}\text { Low income }<\text { AU } \$ 30,000 \\
\text { Middle income AU } \$ 30,000-\$ 80,000 \\
\text { High income }>A \cup \$ 80,000\end{array}$ & $\begin{array}{l}0 \\
7(29) \\
17(71)\end{array}$ \\
\hline Health insurance, n (\%) & $\begin{array}{l}\text { No private health insurance } \\
\text { Combined private health insurance (hospital \& extras) } \\
\text { Private hospital cover only } \\
\text { Private extras cover only }\end{array}$ & $\begin{array}{l}\text { II (46) } \\
7(29) \\
4(17) \\
2(8)\end{array}$ \\
\hline Country of birth, n (\%) & $\begin{array}{l}\text { Australia } \\
\text { India } \\
\text { Cyprus } \\
\text { Kazakhstan } \\
\text { Poland } \\
\text { Russia }\end{array}$ & $\begin{array}{l}18(76) \\
2(8) \\
1(4) \\
1(4) \\
1(4) \\
1(4)\end{array}$ \\
\hline Language spoken by family at home, $\mathrm{n}(\%)$ & $\begin{array}{l}\text { English } \\
\text { Punjabi } \\
\text { Russian }\end{array}$ & $\begin{array}{l}22(92) \\
I(4) \\
I(4)\end{array}$ \\
\hline Number of years family has used CAM, mean \pm SD [years] & Range: $2-51$ & $23 \pm 12.09$ \\
\hline Use CAM singularly or with other therapies, $n(\%)$ & $\begin{array}{l}\text { With other CAM medicines/therapies } \\
\text { Without other CAM medicines/therapies } \\
\text { With biomedicine } \\
\text { Without biomedicine }\end{array}$ & $\begin{array}{l}22(92) \\
2(8) \\
19(80) \\
5(20)\end{array}$ \\
\hline
\end{tabular}

Note: *Some parents provided multiple responses.

Abbreviations: CAM, complementary and alternative medicine; $C B D$, central business district. 
Table 3 Summary of CAM remedies used for the treatment of ARTI in children ( $n=46$ children)

\begin{tabular}{|l|l|}
\hline Remedies & $\begin{array}{l}\text { Number of Children total } \\
\text { of } 46, \mathbf{n}(\%)\end{array}$ \\
\hline Foods as medicine (soups) & $3 \mathrm{I}(67)$ \\
Aromatherapy (e.g. eucalyptus oil) & $30(65)$ \\
Vitamin C & $27(58)$ \\
Honey & $25(54)$ \\
Garlic & $23(50)$ \\
Herbal combination & $20(43)$ \\
Zinc & $19(4 \mathrm{I})$ \\
Ginger & $19(4 \mathrm{I})$ \\
Probiotics & $18(39)$ \\
Echinacea & $17(36)$ \\
Fish oil or essential fatty acids or & $17(36)$ \\
Cod liver oil & \\
Homoeopathic & $17(36)$ \\
Multi-vitamin & $13(28)$ \\
Peppermint (tea) & $1 \mathrm{I}(23)$ \\
Elderflower (tea or tincture) & $1 \mathrm{I}(23)$ \\
Olive leaf & $10(2 \mathrm{I})$ \\
Yarrow & $4(8)$ \\
Essential oil rubs & $4(8)$ \\
Vitamin D & $3(6)$ \\
Turmeric Powder (in food and & $2(4)$ \\
drinks) & $2(4)$ \\
Tiger Balm & $2(4)$ \\
Magnesium soaks & $2(4)$ \\
Onion and Honey & $2(4)$ \\
Celloids & $2(4)$ \\
Tissue Salts & $\mathrm{I}(2)$ \\
Cupping & $\mathrm{I}(2)$ \\
Traditional Tea (e.g. lemon and & \\
honey) & \\
Ivy Leaf & \\
\hline
\end{tabular}

"And it's natural to the body so I'm not worried about side effects, I'm not worried about long term problems." Gemma

A few parents $(n=3,12 \%)$ reported concerns regarding the possibility of problems arising from the use of CAM treatments in their children, such as vomiting and stomach ache:

"My daughter got it when I gave her some olive leaf, and she got an upset tummy." Yelena

Safety of CAM - risks of side effects. There were several parents $(\mathrm{n}=7,29 \%)$ who reported concerns regarding the possibility of side effects as a result of taking a CAM remedy incorrectly or not as prescribed by a CAM practitioner. In the context of this study, we defined a side effect as a predictable negative effect that occurs when treatment is utilised. The treatments could be pharmaceutical products, a CAM remedy (e.g. vitamin or herbal remedy) or CAM therapy (e.g. body manipulation):

"some homoeopathic stuff can have side effects". Fiona

Safety of CAM - "quality" of CAM remedies. Many parents identified the specific CAM product as of crucial importance when deciding which product or remedy to use in the treatment of ARTI in their children. The majority of parents $(n=22,91 \%)$ reported using a particular brand, preferring to purchase the same CAM products/ brands in the management of ARTI for their children. The "quality" of CAM products, such as ingredients, dose and brand, was mentioned by $6(25 \%)$ parents, who discussed the combination of ingredients contained in the CAM products as important:

"The therapeutic actions (of a remedy) ..., make the difference too because I could get an XXXXX (brand) Echinacea, very different to the $\mathrm{XXXXX}$ (brand) Echinacea." Nat

The quality of the remedies was seen as superior when a practitioner prescribed it. Prescription of a remedy by a CAM practitioner was important to over one-third of parents when considering administering remedies to their children. Having a qualified CAM practitioner review the child before giving remedies was paramount in many cases $(66 \%, n=15)$. In fact, some parents did not feel that they could give their child a CAM remedy without first consulting a CAM practitioner:

“... [For] tinctures and that sort of stuff we would get them [the child] reviewed by a naturopath ... I don't just test them and see, we go back and follow up." Abbi

\section{Safety of biomedicine}

In this category, the safety of biomedicine pertains to the safe delivery of biomedicine, and the receipt of biomedical services and products. The safety of biomedicine therefore incorporates consultations with biomedical practitioners and the safety of the medicines themselves. The majority of parents $(n=22,95 \%)$ indicated that their decision to use biomedicine was influenced by the desire to avoid prescribed medications, while acknowledging that biomedicine may be necessary for the treatment of ARTI in their child. 


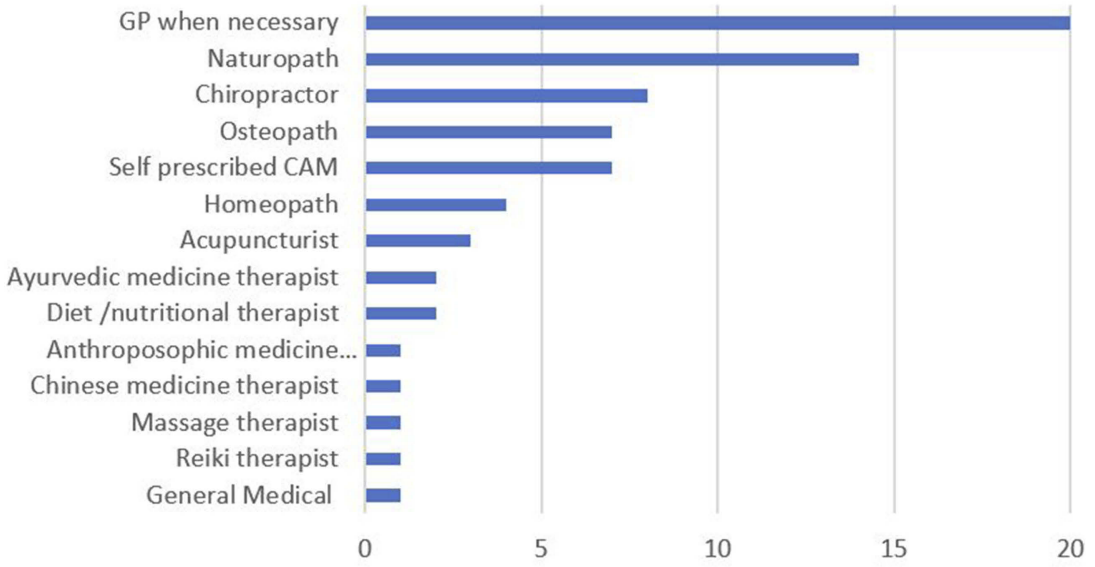

- Practitioners consulted by parents regarding children and ARTI (n)

Figure I Number of complementary and alternative medicine and other health practitioners consulted for acute respiratory tract infection in children over the past 12 months (data for 46 children reporting 72 consultations).

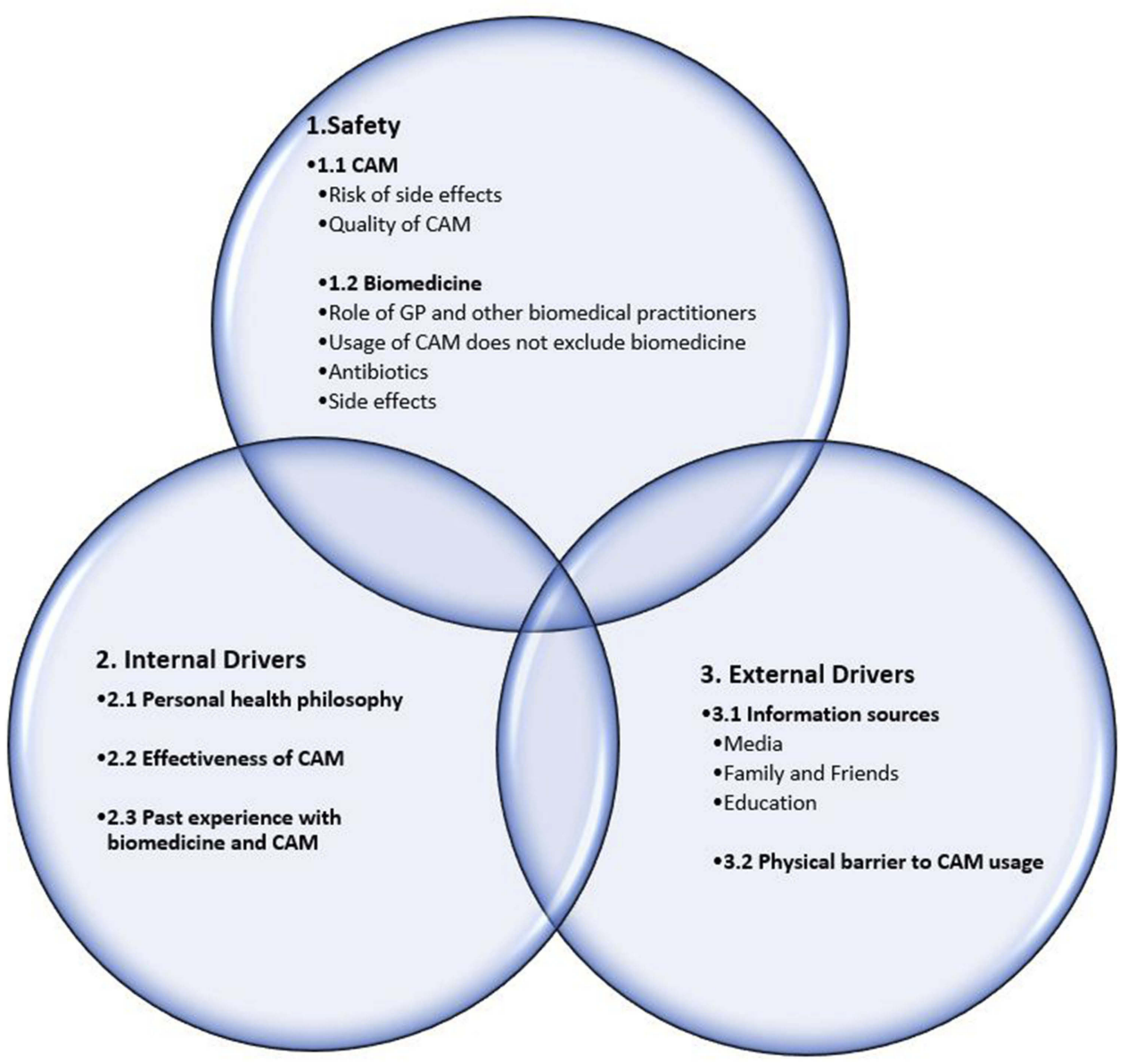

Figure 2 Factors impacting the parental decision-making process when choosing to utilise complementary and alternative medicine for acute respiratory tract infection in their children.

Safety of Biomedicine- the role of GP and other biomedical practitioners regarding the usage of CAM. The role of the GP was an important consideration for parents when deciding to use CAM remedies. A large number of parents $(n=20,83 \%)$ discussed the role of GP's in their decision to use CAM remedies for the treatment of ARTI in their 
children. Parents identified the GP as someone who assessed, diagnosed and/or provided treatment options, and would consult the GP for a diagnosis at the onset of a condition, or when the child's condition changed:

"I would probably take him to a doctor first to make sure there's no infection or anything serious, 'cause they can get a burst eardrum, and I wouldn't want anything to get bad". Olivia

Obtaining a medical diagnosis for ARTI was the key reason for consulting a biomedical practitioner for half of the parents $(n=12,50 \%)$. These parents often did not want medical treatment or a prescription from the practitioner at this point in time:

"Yeah so for otitis media you go to the GP for the GP to have a look, but you don't go for antibiotic [pre]scription."Abbi

Almost half $(45 \%, 11 / 24)$ of parents discussed when they perceived the role of the biomedical practitioner (GP) changing from assessment only, to providing assessment and treatment (intervention). This point where biomedical intervention was sought varied from parent to parent; for some parents, it was measured by time, and others it was measured by symptoms. The parents stated that they would utilise biomedical care when the child's condition deteriorated to a level that they were not comfortable to continue CAM without biomedical input:

"You have to keep an open mind and know when to turn to the pharmaceutical or the medical help when you need it. There is a danger of just relying on CAM to cure everything. Illness may progress too far, or you might need medical intervention.” Kim

Safety of biomedicine - using CAM does not exclude biomedicine. This element of the safety of biomedicine refers to parents utilising both CAM remedies/treatments and biomedicine for the management of ARTI in their children. Parents that utilised CAM for ARTI also sort biomedical care. The majority $(n=22,91 \%)$ of parents reported that they would consult a biomedical practitioner in addition to using CAM remedies to manage ARTI in their children. For these parents, CAM remedies were used in conjunction with biomedical treatment when indicated:

"They've needed to see a doctor to diagnose or to test or XXX with his asthma ... It's not as if I'm not going to give it to him because it's medicine, so I do embrace both. I just know the limitations of both." Poppy
In some cases $(\mathrm{n}=2,8 \%)$, biomedical practitioners were the first point of call for parents, with CAM treatment seen as an adjunct to biomedicine:

"It's $[\mathrm{CAM}]$ never been a replacement for conventional medicine. It's just been a supplement to it. If I'm not well, I'll go to the doctor. If I need antibiotics or whatever, I will take them, but I will take other stuff just to help the body recover." Vanessa

Safety of biomedicine - antibiotics. The use of antibiotics emerged as a critical factor for $20(83 \%)$ parents in their decision to use CAM for ARTI in their children. The desire to minimise the use of antibiotics for the management of ARTI was identified, with the use of antibiotic treatment perceived as a last resort:

"We try to keep away from antibiotics, so we have minimal use of antibiotics in this household. I don't think she's ever had to take antibiotics, touch wood, for her respiratory conditions at all." Jasmine

Parents $(n=8,33 \%)$ expressed concerns regarding the overuse of antibiotic treatment in ARTI's, particularly for viral infections, and the development of antibiotic resistance. The parents' perception was that antibiotics targeted bacterial infections while the majority of ARTI was viral; consecutively rendering antibiotics as ineffective in these circumstances:

"If you're fighting an infection, it's (antibiotic's) are not necessarily going to be a helpful ...... . the infection might be viral so it's actually not going to really do anything." Kim

“. ... a huge problem in our society with antibiotics overuse." Poppy

Safety of biomedicine - side effects. The perceived side effects of biomedicines were a factor influencing parents' decision to utilise CAM treatments for ARTI in their children. Seventeen (70\%) parents spoke about the side effects of biomedical treatments, ranging from disturbances in gut flora to suppression of the immune system. The statements made by parents regarding the side effects of biomedicine ranged from personal experiences (e.g. vomiting) to personal knowledge (antibiotics destroy gut bacteria). Potential side effects of biomedicine were also a concern of parents $(58 \%, 14 / 24)$ when compared to CAM treatments: 
"Well, they destroyed every possible gut bacteria that was there, the good and the bad." Melissa

Safety was important to the parents in their decision-making process when utilising CAM for ARTI in their children. Regarding the safety of the CAM treatments, parents considered the risks of side effects as well as the quality of a CAM product when making choices. Finally, despite the reliance on CAM, parents still used biomedicine as a safety net.

\section{Internal drivers}

Under the broad concept of internal drivers' parents reflected on their thoughts, feelings and attitudes from their personal beliefs and past experiences. Three key components were identified as internal drivers, including personal health philosophy, perceived effectiveness of CAM, and past experiences with biomedicine and CAM.

\section{Internal drivers - personal health philosophy}

Personal health philosophy referred to an individual's health beliefs and the underlying principles of wellbeing and health that drove health care decisions. Many parents $(n=21,87 \%)$ adopted a personal health philosophy based on their perceived importance of the immune system in health and wellbeing:

"We believe it (CAM) treats the cause, ... It's not a BandAid solution. We don't get reoccurrence of things, and it's safe, and it builds their immune system. It supports their immune system in a better way ..." Brooke

To clarify the point, Brooke goes on to talk about how her child had less illnesses than her friends' children, as well as less severe illnesses. For other parents, the importance of holistic health care $(n=4,16 \%)$ was identified as of key importance in their decision making processes:

"I will use that multidimensional approach, so I'll do energetic healing on them. I'll help reduce their stress levels, build up their gut strength to increase their immune system, and help release toxins. ... . I guess the term, "Holistic", gets thrown around, but holistic, that's what it means to me. It's the recognition that we're not just physical, we're physical, mental, emotional, and energetic ..." Catherine

Twenty-one (87\%) parents discussed more specific personal health philosophies, entailing utilising food as medicine as the primary health treatment for ARTI in their children. Some described using foods as medicine in terms of kitchen medicine, or home remedies:
"It's stuff like that you have in your house, ........ A lot of its kitchen medicine ... ...... Yeah. Except we call them home remedies." Laura

" ... food as medicine, ..., you actually do see instant results. If the kids have a bowl of hot chicken soup, then you pretty much know that cleared it up and their ok" Abbi

\section{Internal drivers - effectiveness of CAM}

Parents measured the effectiveness of CAM remedies in two ways: (a) recovery time, defined as how many days their child was ill (from the commencement of symptoms to the cessation of symptoms) as compared to other children in their network, and (b) frequency of illness, defined as how many times a year their child was ill compared to other children in their network. Effectiveness was measured subjectively. The perceived effectiveness of CAM was a strong internal driver of a parent's decision-making. Twenty-three (96\%) parents discussed the effectiveness of CAM:

\begin{abstract}
"They get better faster [using CAM] ... . I'd be at home for a week, a week and a half and missed out on that much work, when I was working [and using biomedicine]. Whereas now, it's a day [I use CAM], maybe two, and they're fine." Elisa
\end{abstract}

Internal drivers - past experience with biomedicine and CAM

The past experiences of parents with biomedicine and CAM appeared to impact strongly on their choices for seeking CAM or biomedicine for the management of ARTI in their children. A parent's perception of how they had been treated by biomedical practitioners (i.e. physically, emotionally and mentally), and the outcome of this treatment, appeared to have an impact on a parent's current health practice. Negative past experiences with biomedicine practitioners, such as feeling emotional discomfort, and feeling that the practitioner was dismissive of CAM, influenced the decision-making of ten (41\%) parents:

"I was 17 and mom took me to a Chinese doctor and put me on this horrendous diet, ... So, I was on this diet for about a month, and I got much better, and I went to see my gastroenterologist ... and I said, "Yeah, I'm doing really well, I've been on this diet, I'm feeling much better." Blah, blah, here comes the eye roll, "Don't be ridiculous; diet has nothing to do with it." Isabel 
A small number of parents $(n=4,16 \%)$ reported having used CAM remedies for generations, with their parents and grandparents using CAM remedies:

“... And then lots of honey and lemon and ginger tea. And if it's a grown up I make the, my grandmother calls it elixir of life, ... cayenne pepper and ... garlic ... honey and ginger." Sonia

Use of CAM for ARTI in their children were impacted by interactions with biomedical practitioners, as well as past experiences with CAM. Many parents ( $\mathrm{n}=13,54 \%)$ reported negative past experiences with biomedicine:

"They [biomedical practitioners] are either negative or just dismissive." Queenie

All parents $(\mathrm{n}=24,100 \%)$ articulated positive past experiences with CAM. This was expressed by the parent observations of their children's recovery from ARTI as well as personal stories of past positive experience:

"I had to do a bit of a few changes, food, and lifestyle, and medicine, particularly allergy treatment and medication free, symptom-free. I don't get asthma. I don't get hay fever." Poppy

One parent $(4 \%)$ expressed a negative experience with CAM for herself as a child, but overall, she reported having a positive experience with CAM for ARTI in her children:

"She cupped me. I remember she cupped me ... I remember it was a very traumatic experience for me." Elisa

Personal ideas, beliefs and opinions represented important internal drivers of a parent's decision to use CAM for the management ARTI in their children.

\section{External drivers}

The third category related to the broad concept of external drivers. In this category, parents reflected on the factors influencing their decision to utilise CAM from a social, environmental and system perspective. This included deliberating on the types of information sources used, as well as the accessibility, cost and compliance with CAM treatments. External drivers were grouped into two components: information sources used by parents when deciding to use CAM therapies, and the physical barriers encountered by parents that limited their access to CAM treatments.

\section{External drivers - information sources}

The information sources used by parents to help them decide on whether to use CAM as a first line treatment for ARTI in their children were grouped into three elements. These included media (online and mainstream), consultation with family and friends, and education (formal and informal study).

External drivers - information sources [media]. A vital information source used by parents to guide their decision making was the media, including online and mainstream media. Online media included both social media (for example, Facebook and Instagram), and the internet (including the use of publicly available search engines such as Google and Google Scholar). Google was a favorite search engine for parents conducting general internet searches on CAM, although it was not the only search engine used:

"I'll go on Google, and I'll go into PubMed." Olivia

"A lot of the time Google Scholar." Queenie

Some parents were a little more hesitant about using Google to find information on CAM and ARTI, as one parent stated:

"I will Google things occasionally. I'm quite sort of, wary about what I want, cause most of it seems to me to be put there by people who sell vitamins." Yelena

Mainstream media sources used by parents included traditional journalistic outlets such as television and radio. Nineteen (79\%) parents identified such media as an essential information source for making decisions regarding the use of CAM for ARTI in their child. Of the $79 \%$ that used media, just over half ( $n=13,54 \%$ ) of parents did not use the internet (especially Google) to find information on CAM for ARTI:

"No. I must admit, I'm not a Dr. Google kind of person.

I'll actually go to sort of more trusted sources." Catherine

Some parents were quite skeptical regarding information obtained via the mainstream media:

"I don't trust the information that comes out of the media because it's not necessarily backed up. It's a lot of the opinions again." Heide

By contrast, there were some mainstream media sources that parents did trust, particularly those that were noncommercial: 
"So, the healthy report of Radio National is very good show on." Yelena

The use of social media was mixed, with some parents $(n=7,29 \%)$ not using social media at all, and some $(n=7$, $29 \%$ ) using it frequently:

“[I use] 3-4 Facebook groups.” Brooke

"Definitely not Facebook." Yelena

External drivers - information sources [family and friends]. Most parents $(n=20,83 \%)$ consulted family and friends as an information source to inform decision making about CAM use for ARTI. Family members included mothers, grandmothers, husbands, sisters, brothers and sisters-in-law. Friends included school or preschool networks, social networks, and work colleagues. Seventeen (70\%) parents made positive comments about utilising family and friends:

"I think it's because a friend of mine found it really valuable at one point, and she really recommended it ...." Yelena

Family did not appear to influence some parents at all $(n=3,12 \%)$, with one $(4 \%)$ parents receiving negative comments from family members regarding CAM usage:

"[I use CAM] even though my family yells at me a lot when I do it (use CAM) and call me like the worst mum in the world." Sonia

When parents were deciding to give CAM to their child with ARTI, friends were a sought-after information source. Nine (38\%) parents mentioned friends as the primary information source:

"We'll do knowledge sharing a lot. Whatever we have learned through other experiences." Laura

External drivers - information sources [education]. Parents had obtained formal and informal education in CAM. Some parents undertook qualifications in CAM $(n=6,25 \%)$ or workshops on CAM topics, and others read relevant journal articles $(n=3,12 \%)$. There was not one particular information source that was consistently utilised by all parents to assist them in making decisions regarding the management of ARTI with CAM. One parent would rely on one information source, and another would disregard that same information source.

Using academic/professional journals as an information source to guide decision making, varied among parents. This appeared to be driven by other factors, such as occupation, of which one parent was required to read peerreviewed journals for work purposes:

"Yes, because I have to read them (peer-reviewed journals)

for work." Isabel

However, for some parents $(n=2,8 \%)$, journal articles were not a preferred information source:

"Not journals. I probably read people's blogs and decide whether I think they're valid or not. I probably do a little bit of Googling, maybe ...." Kim

Other parents $(n=8,33 \%)$ utilised a combined approach, drawing information from a range of sources in order to inform their decision making:

"A lot of it is anecdotal stuff. Looking on the internet. Research papers. Talking to friends. Talking to my mom's naturopath. Old wives tales I suppose ... ... ... . Mostly internet or trusted friends, really.” Ruby

\section{External drivers - physical barriers to CAM usage}

There were several physical barriers that affected a parent's decision to use CAM for ARTI in their children. Barriers were mentioned by $70 \%(n=17)$ of parents. These barriers included the cost of CAM consultations, the cost of prescribed CAM remedies, the time taken to consult a CAM practitioner versus accessing over-thecounter remedies, lack of government rebates, and the poor palatability of some remedies. The barriers that the parents mentioned did not prevent CAM usage but limited the number of times they would use CAM. If the barriers were addressed, the parent felt that they would utilise CAM more frequently than they presently do. Fifteen $(62 \%)$ parents alluded to cost as being the most important barrier.

Also relating to cost, parents identified the current national health scheme (Medicare) as a barrier, which does not provide rebates for CAM consultations. Of related concern was the cost of CAM provider appointments and the cost of practitioner-only remedies, both of which impacted the parent's access to CAM. The cost of remedies sold by practitioners compared with remedies sold by supermarkets, pharmacies, and health food stores was also discussed, with remedies sold by supermarkets, pharmacies, and health food stores recognised as being relatively cheaper and thus more accessible to parents: 
“... it $[\mathrm{CAM}]$ is expensive. It's expensive for the products, it's expensive for food, and it's expensive to see the practitioner. So, it's a huge expense" Sonia

Other parents $(n=6,25 \%)$ believed the use of CAM was cost-effective in the long-term as it resulted in them needing less time off work to look after children when they were sick:

"So far it's [using CAM] been cost-effective in that so far I've had to take less time off work which is really good." Fiona

Some parents $(n=3,16 \%)$ also pointed out the potential problems or risks associated with using cheaper CAM remedies:

“... 'cause in the supermarket, they're so cheap ... you're not really paying for what you get. So, you're getting a poor quality, but you pay a lot more money for a goodquality product." Nat

Time also influenced a parent's decision to utilise CAM. This mainly referred to the time required to see a practitioner, relative to the short time needed to visit a pharmacy or shop to buy a CAM remedy:

"It's [using CAM services] is definitely more time-consuming." Tania

Another physical barrier to CAM usage was the palatability of some CAM remedies. Eight $(n=8,33 \%)$ parents stated that their children did not like the taste or were not able to swallow some CAM remedies:

"We don't use them as preventatives or such most of the time. Mainly because I did try that, but they don't like the taste of the (CAM remedies) ... and XXXX won't take tablets." Vanessa

Various external drivers appear to impact a parent's decision to utilise CAM for ARTI in their children; in particular, time, money and information source.

\section{Discussion}

The purpose of this research was to gain an understanding of the treatments, and the factors that influence a parent's decision to utilise CAM for the treatment of childhood ARTI. The most common remedies utilised by parents for their children with ARTI were "kitchen remedies" (food as medicine) followed by aromatherapy. This finding that food as medicine is the most frequently used CAM remedy is supported by a previous review. ${ }^{23}$ The everyday use of food as medicine is likely due to a combination of reasons, including familiarity, ease of access and the perception that food is safer and more palatable (as it is consumed regularly) when compared to other CAM remedies (e.g. herbs, vitamins and minerals). However, this is contrary to other research findings, that point to non-vitamin/non-mineral supplements (e.g. fish oil), ${ }^{42}$ clinical nutrition, ${ }^{7}$ and chiropractic or herbal remedies ${ }^{9,43}$ as the types of CAM most frequently used in the general adult population. These differences may be explained by the nature of the condition (general health vs ARTI) and the patient population (adults vs children).

Despite many different factors influencing the decision-making processes of parents, some common influences emerged. One major driving factor for parents was the child's safety, in particular, the need to limit the use of antibiotics. One might suggest that there is some logic to this argument. For instance, antibacterial resistance is a global health emergency, ${ }^{44}$ of which a major contributor is excessive antibiotic exposure. ${ }^{45}$ The paediatric population has the highest antibiotic exposure of any age group, globally, ${ }^{46}$ and in the UK, about half all antibiotic prescriptions are for ARTI. ${ }^{24,47}$ Accordingly, parents utilised CAM as an initial treatment for ARTI based on an understanding that antibiotics were not an ideal first-line treatment for their child's condition (particularly for infections of viral origin). Notwithstanding, this did not prevent parents from consulting a biomedical practitioner for assessments to confirm their child's diagnosis, or if the child was not responding to CAM treatment. ${ }^{48-50}$

The parental decision-making process regarding the utilization of CAM for ARTI in children was often complex, with parents constantly re-evaluating the decisions made during their child's illness. For example, at what point should I, the parent, consult a biomedical practitioner? Parents often utilised a step-down decision-making approach, involving internal and external drivers, as well as diverse practitioners (including biomedical and CAM). Parents drew a hypothetical line in the sand regarding when they evaluated the use of CAM treatments and consulted biomedical practitioners. This point differed from family to family, but the parents were quite definite when the change in care occurred concerning a particular time point or symptom development. The key driver appeared to be the safety of their child. If parents believed the child's condition was increasing in severity, the parents recognised that a review of care was required. The perceived severity of a child's condition has featured in 
previous research and the decision to consult a biomedical practitioner. $^{24,48,49,51,52}$ This appears to be the same for parents that utilise CAM treatment.

The steps in the parental decision-making process first involved parents assessing their child, either themselves or by a practitioner (either CAM or biomedical). The parents would then start with (self-prescribed) $\mathrm{CAM},{ }^{53}$ predominately home remedies (kitchen medicine or food as medicine). If the child's condition did not appear to improve or the condition stayed the same, they would consult a health practitioner (either CAM or biomedical), and if perceived safe to do so, they would continue with CAM. If the child symptoms still did not improve or a certain amount of time passed (1-3 days), then the parent would arrange a biomedical consultation. This biomedical consultation could be with a general medical practitioner or at an emergency department in a hospital. At this stage, the parents were requiring assessment and treatment of their child's ARTI (Figure 3). The parent's decision-making in this step-down process was driven by the desire for the child to have effective and safe health care. Parents stated that they rarely, if ever reached the final step of biomedical treatment when utilising CAM.

Previous research in the area of healthcare decisionmaking suggests that people often draw from information sources that are within close reach, such as their friends, family, self-education, media, and the internet. ${ }^{14,53-55}$ This was also the case in our study, where parents tended to rely on similar information sources to guide their decisionmaking, although the types of resources used were not consistent (e.g. some parents utilised media and others did not). Parent's also referred to CAM practitioners for advice on the use of CAM for ARTI in their children; however, general biomedical practitioners often did not play a role in their decision-making. These findings are supported by other research involving Australian children ${ }^{8}$ and women. ${ }^{55}$ The parent's reliance on friends and family to inform decisions regarding CAM use is similarly supported by research of US children with asthma. ${ }^{56}$ While other research points to biomedical practitioners being the primary source of information in parent healthcare decision-making, ${ }^{15}$ this was not the case in these parents managing childhood ARTI with CAM, where the primary source of information was families and friends.

The findings of this study suggest a push away from biomedicine (negative experiences) and a pull towards CAM (positive experience and influences) may be important drivers in the parent's decision-making process. A similar paradigm shift has been reported among older people using $\mathrm{CAM},{ }^{55}$ where biomedicine was considered undesirable and CAM was reported as beneficial. The push away from biomedicine encompassed parent's health philosophy, a desire to limit the use of antibiotics in their children, the negative past experience with biomedicine, and the perceived undesirable impact of biomedicine on their child's body. The pull towards CAM included the perceived effectiveness of CAM, information sources encouraging CAM usage, and the perception that CAM is a safer option.

Parents expressed a desire for integrated healthcare, rather than a complementary and alternative medicine versus biomedical approach. In most cases, parents did not avoid biomedical care; instead, parents sought ways to blend biomedical and CAM health approaches, with the common goal of maximizing health, diminishing illness, and preventing disease. ${ }^{57}$ Indeed, there is evidence to suggest that many people (including the parents in this study) have a preference for healthcare that includes the

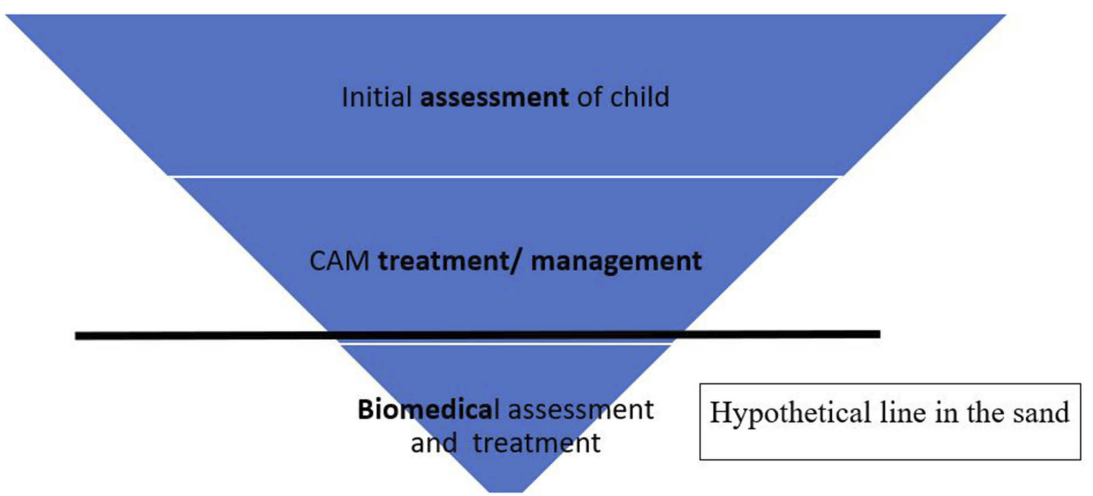

Figure 3 Hypothetical line in the sand for parents when making decisions regarding complementary and alternative medicine use for acute respiratory tract infection in children. 
services of both CAM practitioners and biomedical practitioners. $^{58,59}$

\section{Limitations}

Despite generating new knowledge about CAM utilization among parents of children with ARTI, this research did have some limitations. Given the qualitative nature of this study, the generalisability of this research is limited. However, given the extensive recruitment strategies implemented, and continuation of data collection until no new information was gleaned, suggests that this research does provide useful insights that can be relevant to the field of CAM use for ARTI in children. The sample in this research were all women and from English-speaking backgrounds, which may limit the generalisability of these findings to a wider population. While this is an important limitation to consider, the sample from this research aligns with previous research on the characteristics of a typical CAM user, who are namely females with a higher education and from a higher socioeconomic background., 93,60 Another limitation of this research was the exclusion of children with chronic immune disorders as they were likely to be already exposed to other CAM modalities. This exclusion may limit the generalizability of the research findings to this cohort of children. As is the norm with any qualitative research, data from the interviews were analysed and presented as distinct categories and sub-categories. While this is a useful manner to present the data, it must also be acknowledged that these categories and sub-categories are inevitably inter-linked as they are derived by individual perspectives and are not necessarily stand-alone constructs. Another possible limitation may be the lack of member checking. While this has been purported to be rigour strategy in the past, currently there is debate regarding its usefulness. ${ }^{35}$ As a means of addressing this limitation, a range of other strategies to enhance rigour were undertaken, such as the use of multiple coders, triangulation of research with multiple viewpoints, and triangulation of the sample from different settings.

\section{Clinical implications}

A parent's decision to use CAM for the management of childhood ARTI is underpinned by a complex and nuanced decision-making process. While parents used a range of diverse sources to inform their decision making, they also engaged with mainstream medicine as well. To that end, CAM remedies, as per their namesake, are used to complement mainstream treatments. Food as medicine was the most commonly used CAM remedy, which maybe reflected familiarity with, and access to, readily available resources for parents. From a clinical point of view, these findings highlight the critical role of CAM in the management of ARTI in children, its common practice in the community, and the preference among parents for an integrative approach to healthcare (i.e. bringing together mainstream and complementary medicine services).

\section{Conclusion}

For some parents of children with ARTI, CAM appears to provide a viable treatment option. Parents seemed to rely on a range of CAM remedies to treat ARTI, with food as medicine often acting as the "first cab of the rank". A parent's decision to use CAM seemed to be influenced by a multitude of factors, ranging from personal perspectives to external information sources. Parents also consulted a range of CAM practitioners to inform their decision making, but also relied on biomedical practitioners (often at the same time) either to obtain an initial diagnosis or to provide treatment when the child did not improve as expected (by the parent). This showcases a nuanced approach by parents, who seem to carefully balance the safety and effectiveness of CAM with biomedicine. It also points to a preference among parents for an integrative approach to the management of ARTI in children.

\section{Ethics approval and consent to participate}

The Human Research Ethics Committees of the University of South Australia (ID: 0000035018) and Department of Education and Training (Victoria) (ID: 2016_003142) granted ethics approval. Informed consent was obtained from each participant. All participants were given pseudonyms.

\section{Consent for publication}

Written consent was obtained from all participants for data to be used in this publication.

\section{Availability of data and material}

The datasets generated during and/or analysed during the current study are available from the corresponding author on reasonable request. 


\section{Abbreviations}

ARTI, acute respiratory tract infection; AUS, Australian dollar; CAM, complementary and alternative medicine; $\mathrm{CBD}$, central business district; $\mathrm{QD}$, qualitative descriptive; GP, general medical practitioners.

\section{Acknowledgments}

The authors thank the participants for taking part in the study. Ms. Lucas acknowledges the Australian Government Research Training Program Scholarship that funds her PhD.

\section{Author contributions}

SL participated in the study concept and design, data acquisition, data analysis, data interpretation, manuscript drafting, critical revision of the manuscript, and the final review of the manuscript. SK participated in the study concept and design, data analysis, data interpretation, manuscript drafting, critical revision of the manuscript, and the final review of the manuscript. MJL participated in the study concept and design, data analysis, data interpretation, manuscript drafting, critical revision of the manuscript, and the final review of the manuscript. AP participated in the data interpretation, manuscript drafting, critical revision of the manuscript, and the final review of the manuscript. All authors approved the final version to be published and agree to be accountable for all aspects of the work.

\section{Disclosure}

The authors report no conflicts of interest in this work.

\section{References}

1. National Center for Complementary and Integrative Health, National Center for Health Statistics, editors. The Use of Complementary and Alternative Medicine in the United States. USA: Services USDoHaH, ed;2008.

2. MacLennan A, Myers S, Taylor A. The continuing use of complementary and alternative medicine in South Australia: costs and beliefs in 2004. Med J Aust. 2006;184(1):27-31.

3. Wieland LS, Manheimer E, Berman BM. Development and classification of an operational definition of complementary and alternative medicine for the Cochrane collaboration. Altern Ther Health Med. 2011;17(2):50-59.

4. Italia S, Wolfenstetter SB, Teuner CM. Patterns of complementary and alternative medicine (CAM) use in children: A systematic review. Eur $J$ Pediatr. 2014;173(11):1413-1428. doi:10.1007/s00431-014-2300-z

5. Cincotta DR, Crawford NW, Lim A, et al. Comparison of complementary and alternative medicine use: Reasons and motivations between two tertiary children's hospitals. Arch Dis Child. 2006;91(2):153-158. doi:10.1136/adc.2005.074872

6. Smith C, Eckert K. Prevalence of complementary and alternative medicine and use among children in South Australia. J Paediatr Child Health. 2006;42(9):538-543. doi:10.1111/jpc.2006.42.issue-9
7. Xue C, Zhang A, Lin V, Da Costa C, Story D. Complementary and alternative medicine use in Australia: a National population-based survey. J Altern Complement Med. 2007;13:643-650. doi:10.1089/ acm.2006.6355

8. Frawley J, Anheyer D, Davidson S, Jackson D. Prevalence and characteristics of complementary and alternative medicine use by Australian children. $J$ Paediatr Child Health. 2017;53:8. doi:10.1111/jpc. 13555

9. Frass M, Strassl RP, Friehs H, Müllner M, Kundi M, Kaye AD. Use and acceptance of complementary and alternative medicine among the general population and medical personnel: a systematic review. Ochsner J. 2012;12(1):45-56.

10. Australian Bureau of Statistics. Australian Social Trends 2008.cat No 04102.0. Australia: Commonwealth of Australia; 2008.

11. Zuzak T, Bonkova J, Careddu D, et al. Use of complementary and alternative medicine by children in Europe: published data and expert perspectives. Complement Ther Med. 2013;21(1):S34-S47. doi:10.1016/j.ctim.2012.01.001

12. Marmoreo J, Brown JB, Batty HR, Cummings S, Powell M. Hormone replacement therapy: determinants of women's decisions. Patient Educ Couns. 1998;33(3):289-298.

13. Barona-Vilar C, Escribá-Agüir V, Ferrero-Gandía R. A qualitative approach to social support and breast-feeding decisions. Midwifery. 2009;25(2):187-194. doi:10.1016/j.midw.2007.01.013

14. Knapp C, Madden V, Marcu M, et al. Information seeking behaviors of parents whose children have life-threatening illnesses. Pediatr Blood Cancer. 2011;56(5):805-811. doi:10.1002/pbc.22674

15. Kilicarslan-Toruner E, Akgun-Citak E. Information-seeking behaviours and decision-making process of parents of children with cancer. Eur $J$ Oncol Nurs. 2013;17(2):176-183. doi:10.1016/j.ejon.2012.03.001

16. Lim AG, Cranswick N, Skull S, South M. Survey of complementary and alternative medicine use at a tertiary children's hospital. $J$ Paediatr Child Health. 2005;41(8):424-427. doi:10.1111/j.14401754.2005.00659.x

17. Ozturk C, Karayagiz G. Exploration of the use of complementary and alternative medicine among Turkish children. J Clin Nurs. 2008;17 (19):2558-2564. doi:10.1111/j.1365-2702.2008.02329.x

18. Johnson S, Capdevila R. 'That's just what's expected of you ... so you do it': Mothers discussions around choice and the MMR vaccination. Psychol Health. 2014;29(8):861-876. doi:10.1080/ 08870446.2014.892940

19. Bonevski B, Wilson A, Henry DA. An analysis of news media coverage of complementary and alternative medicine. PLoS One. 2008;3(6):e2406. doi:10.1371/journal.pone.0002406

20. Ernst E, Weihmayr T. UK and German media differ over complementary medicine. $\mathrm{Br}$ Med J. 2000;321(7262):707. doi:10.1136/ bmj.321.7274.1450

21. Thorne S, Paterson B, Russell C, Schultz A. Complementary/alternative medicine in chronic illness as informed self-care decision making. Int J Nurs Stud. 2002;39(7):671-683.

22. Sirois F. Motivations for consulting complementary and alternative medicine practitioners: A comparison of consumers from 1997-8 and 2005. BMC Complement Altern Med. 2008;8:16. doi:10.1186/14726882-8-62

23. Lucas S, Leach M, Kumar S. Complementary and alternative medicine utilisation for the management of acute respiratory tract infection in children: A systematic review. Complement Ther Med. 2018;37:158-166. doi:10.1016/j.ctim.2018.03.001

24. Cabral C, Lucas PJ, Ingram J, Hay AD, Horwood J. "It's safer to ..." parent consulting and clinician antibiotic prescribing decisions for children with respiratory tract infections: an analysis across four qualitative studies. Soc Sci Med. 2015;136-137:156-164. doi:10.1016/j.socscimed.2015.05.027

25. Leder K, Sinclair MI, Mitakaki TZ, Hellard ME, Forbes A, Fairley CK. A community-based study of respiratory episodes in Melbourne, Australia. Aust N Z J Public Health. 2003;27(4):399-404. 
26. Chen Y, Kirk MD. Incidence of acute respiratory infections in Australia. Epidemiol Infect. 2014;142:1355-1361. doi:10.1017/ S0950268814000211

27. Kotsimboz T, Armstrong D, Buckmaster N, et al. Respiratory Infectious Disease Burden in Australia. The Thoracic Society of Australia and New Zealand (TSANZ). The Australian Lung Foundation; 2007.

28. Nair H, Nokes DJ, Gessner BD, et al. Global burden of acute lower respiratory infections due to respiratory syncytial virus in young children: a systematic review and meta-analysis. Lancet. 2010;375 (9725):1545-1555. doi:10.1016/S0140-6736(10)60206-1

29. World Health Organization (WHO). Coughs and cold remedies for the treatment of acute respiratory infections in young children. In: Development DoCaAHa, editor. Geneva, Switzerland: WHO; 2001. Available from:: http://apps.who.int/iris/bitstream/10665/66856/1/ WHO_FCH_CAH_01.02.pdf?ua=1\&ua=1

30. Zeng L, Zhang L, Hu Z, et al. Systematic review of evidence-based guidelines on medication therapy for upper respiratory tract infection in children with AGREE instrument. PLoS One. 2014;9(2):e87711e87711.

31. Tashakkori A, Teddlie C. Handbook of Mixed Methods in Social and Behavioral Research. Thousands Oaks, California: Sage; 2003.

32. Creswell J. Research Design:- Qualiative,quantitative, and Mixed Methods Approaches. USA: SAGE Publications,Inc.; 2014.

33. Morgan DL. Paradigms lost and pragmatism regained. J Mix Methods Res. 2007;1(1):48-76. doi:10.1177/2345678906292462

34. Saunders M, Lewis P, Thornhill A. Research Methods for Business Students. 6th ed. UK: Pearson Education Limited; 2012.

35. Polit D, Beck C. Nursing Research:- Generating and Assessing Evidence for Nursing Practice. China: Wolters Kluwer| Lippincott Williams \& Wilkins; 2012.

36. Sandelowski M. Focus on Research Methods. Whatever happened to qualitative description? Res Nurs Health. 2000;23 (4):334-340. doi:10.1002/1098-240X(200008)23:4<334::AIDNUR9 $>3.0 . \mathrm{CO} ; 2-\mathrm{G}$

37. Polit DF, Beck CT. Essentials of Nursing Research: Appraising Evidence for Nursing Practice. 7th ed. Philadelphia: Wolters Kluwer Health/Lippincott Williams \& Wilkins; 2010.

38. Tong A, Sainsbury P, Craig J. Consolidated criteria for reporting qualitative research (COREQ): a 32-item checklist for interviews and focus groups.. Int J Qual Health Care. 2007;19(6):349-357. doi:10.1093/intqhe/mzm018

39. Elo S, Kyngas $\mathrm{H}$. The qualitative content analysis process. $J A d v$ Nurs. 2008;62(1):107-115. doi:10.1111/j.1365-2648.2007.04569.x

40. Vaismoradi M, Turunen T, Bondas T. Content analysis and thematic analysis: Implications for conducting a qualitative descriptive study. Nurs Health Sci. 2013;15(3):398-405. doi:10.1111/nhs. 12048

41. Crowe M, Inder M, Porter R. Conducting qualitative research in mental health: Thematic and content analyses. Aust $N Z J$ Psychiatry. 2015;49(7):616-623. doi:10.1177/0004867415582053

42. Clarke TC, Black LI, Stussman BJ, Barnes PM, Nahin RL. Trends in the Use of Complementary Health Approaches among Adults: United States, 2002-2012 Natl. Health Stat. Rep., 79 (2015). Hyattsville, MD: National Center for Health Statistics; 2015:1-16.

43. Leach MJ, Lauche R, Zhang AL, et al. Characteristics of herbal medicine users among internal medicine patients: A cross-sectional analysis. J Herb Med. 2017;10:59-63. doi:10.1016/j.hermed.2017. 06.005
44. World Health Organization (WHO). Antimicrobial Resistance: Global Report on Surveillance. Geneva, Switzerland: World Health Organization, WHO; 2014.

45. Shaban RZ, Cruickshank M, Christiansen K, Committee. tARS National Surveillance and Reporting of Antimicrobial Resistance and Antibiotic Usage for Human Health in Australia. Canberra, Australia: Commonwealth of Australia; 2013.

46. Anderson H, Vuillermin P, Jachno K, et al. Prevalence and determinants of antibiotic exposure in infants: A population-derived Australian birth cohort study. J Paediatr Child Health. 2017;53 (10):942-949. doi:10.1111/jpc.13616

47. Standing Medical Advisory Committee. The Path of Least Resistance. London, England: Standing Medical Advisory Committee Sub-Group on Antimicrobial Resistance; 1998.

48. Kai J. Parents' difficulties and information needs in coping with acute illness in preschool children: a qualitative study. Br Med J. 1996;313 (7063):987-990. doi:10.1136/bmj.313.7063.987

49. Ingram J, Cabral C, Hay AD, Lucas P, Horwood J. Parents' information needs, self-efficacy and influences on consulting for childhood respiratory tract infections: a qualitative study. BMC Fam Pract. 2013;14:106. doi:10.1186/1471-2296-14-106

50. Neill S. Acute childhood illness at home: the parents' perspective. $J$ $A d v \quad$ Nurs. 2000;31(4):821-832. doi:10.1046/j.1365-2648.2000. 01340.x

51. Wyke S, Hewison J, Russell IT. Respiratory illness in children: what makes parents decide to consult?. Br J Gen Pract. 1990;40:226-229.

52. Cornford CS, Morgan M, Risdale L. Why do mothers consult when their children cough?. Fam Pract. 1993;10(2):193-196. doi:10.1093/ fampra/10.2.193

53. Clayton K, Luxford Y, Stupans I. Decision-making factors of pharmacy customers purchasing over-the-counter complementary and alternative medicine for stress. Adv Integr Med. 2017;4(3):103-108. doi:10.1016/j.aimed.2017.12.007

54. Brashers DE, Goldsmith DJ, Hsieh E. Information Seeking and Avoiding in Health Contexts. Hum Commun Res. 2002;28(2):258271. doi:10.1111/hcre.2002.28.issue-2

55. McLaughlin D, Lui C-W, Adams J. Complementary and alternative medicine use among older Australian women - a qualitative analysis. BMC Complement Altern Med. 2012;12:34. doi:10.1186/1472-688212-34

56. Freidin B, Timmermans S. Complementary and alternative medicine for children's asthma: satisfaction, care provider responsiveness, and networks of care. Qual Health Res. 2008;18(1):43-55. doi:10.1177/ 1049732307308995

57. Jansons LL, Lynch RL, LeBlanc A, Tilburt JC. Shared decision making in complementary and alternative medicine therapies. Pediatr Ann. 2012;41(12):522-527. doi:10.3928/00904481-20121 126-14

58. Family H, Jordan A, Blaxall K, Sengupta R. A truly complementary approach: a qualitative exploration of complementary and alternative medicine practitioners' views of treating ankylosing spondylitis. Musculoskeletal Care. 2018;16(1):96-102. doi:10.1002/msc.1217

59. Leach M, Wies EM, Agnew T, Thakkor M. Health consumer and health provider preferences for an integrative health care service delivery model: a national cross-sectional study Int J Clin Pract. 2018;72:6. doi:10.1111/ijcp.13204

60. Eardley S, Bishop FL, Prescott P, et al. A systematic literature review of complementary and alternative medicine prevalence in EU. Forsch Komplementmed. 2012;19(Suppl 2):18-28. doi:10.1159/000342708 


\section{Publish your work in this journal}

The Journal of Multidisciplinary Healthcare is an international, peerreviewed open-access journal that aims to represent and publish research in healthcare areas delivered by practitioners of different disciplines. This includes studies and reviews conducted by multidisciplinary teams as well as research which evaluates the results or conduct of such teams or healthcare processes in general. The journal covers a very wide range of areas and welcomes submissions from practitioners at all levels, from all over the world. The manuscript management system is completely online and includes a very quick and fair peer-review system. Visit http://www.dovepress.com/testimonials. php to read real quotes from published authors. 